\title{
Lessons learned from the implementation of a Service Management Office: the case of a World Food company in Latin America
}

\author{
Teresa Lucio-Nieto ${ }^{a}$, Dora Luz González-Bañales ${ }^{\text {b }}$ \\ ${ }^{\text {a }}$ Universidad Iberoamericana Santa Fe, Ciudad de Mexico; ITESM Instituto Tecnológico y de \\ Estudios Superiores de Monterrey, Monterrey, Mexico, tlucio@terelucio.com \\ ${ }^{\mathrm{b}}$ Computer \& Systems Department, Instituto Tecnológico de Durango, Tecnológico Nacional de \\ México. Durango, Dgo., Mexico, doraglez@itdurango.edu.mx.
}

\begin{abstract}
This paper presents the case of evolution and lessons learned in information technology service management (ITSM) of a World Food Company in Latin America, with an emphasis on their process-driven strategy for integral transformation through the Information Technology Infrastructure Library (ITIL), as well as the creation of their Service Management Office (SMO). Their experience in implementing ITIL and an SMO presenting their roadmap and main challenges. As an extra added value, service quality has been enhanced through the use of business indicators and commitments from three perspectives: people, processes and technologies. These results reveal that the SMO has become a strategic complement for IT, in addition to being a fundamental element to ensure quality and efficiency in technology service management.
\end{abstract}

Keywords: Service Management Office, ITSM, IT Governance, Service Management Department, ITIL

\section{Introduction}

The shift in expectancies regarding the use of information technologies (IT) has caused that today, companies from a range of sectors and sizes seek for increasingly efficient and innovative technology solutions. And so, organizations - especially multinational ones are increasingly recognizing that IT services are crucial and strategic assets that call for resource investment to support their provision and management. However, it is also true that, at times, the strategic role of IT services is overlooked or is not addressed with the strategic importance it entails (Adison Cartlidge et al., 2007), and, those who do recognize its importance through implementation of best practices or IT service frameworks, such as Information Technology Infrastructure Library (ITIL), have found that one of the success 
factors to ensure successful outcomes in managing such services is having an adequate process not just for implementation, but also for follow-up, maintenance (Neničková, 2011) and evolution.

In light of an analysis of literature on the importance of having an office allowing supporting and following up on effective IT service management from the implementation of an IT service management framework (Cannon, 2011; Fry, 2008; ITGI, 2009; LucioNieto \& González-Bañales, 2019; Lucio-Nieto, González-Bañales, \& Bermeo Andrade, 2016; Microsoft, 2008; Plexenet, 2011; Roller, 2009; Shahsavarani \& Shaobo, 2011), the sources analyzed suggest the existence of a Service Management Office (SMO) as a mechanism responsible for delivering quality IT services to users, at both the tactical and strategic levels (Lucio-Nieto \& González-Bañales, 2019; Lucio-Nieto et al., 2016; Montgomery, 2011). Such office's main responsibilities are the strategy and design of a service that delivers business value and the governance of IT processes, frameworks, methodologies and standards (Hubbert, 2008). This is empirically supported by studies conducted in 2009 and 2012 (Lucio-Nieto \& Colomo-Palacios, 2012; Lucio Nieto \& Gonzalez-Bañales, 2009) on a number of Latin American companies in order to know the importance and implications of the implementation of frameworks and best practices in IT service management, as well as the pertinence of the creation of an SMO, considering ITIL as the main framework for IT service management. The results from such studies and a bibliographic review, suggest that it is advisable to have an office allowing following up on and meeting the objectives of IT service management.

Although there is no standard definition for a Service Management Office (SMO), its functions and scope (Lucio-Nieto, 2011), by analyzing several definitions, (Cannon, 2011; Clyton, 2012; Hubbert, 2008; Montgomery, 2011; Roller, 2009) it can be said that it embodies an IT governance mechanism that defines, monitors and audits both operating and in-transition process, it is responsible for ensuring compliance of the "end-to-end" service strategy for all of the functions involved in its definition, design, transition, operation and continual improvement; additionally, it has three main responsibilities: strategy and design of services that deliver business value (demand, portfolio and service catalogue management), and is in charge of business relationships and responsible for the governance of IT processes, frameworks and standards.

Considering that the bibliographic review performed does not include an analysis of a company case that has implemented an SMO in a Latin American setting for a multinational, multi-product company, a study case is presented in this work with the aim of analyzing the lessons learned in the implementation of an SMO in the context of IT 
services, as a means to ensure efficiency and permanence in the implementation of frameworks in the IT service management area, specifically for ITIL.

\section{Lessons learned from the implementation of a Service Management Office (SMO)}

\subsection{Company Background}

World Food Company ${ }^{1}$ (WF) is a leading company in the food (snacks, candies, cookies) and drinks sector, founded in 1898 and operating in over 200 countries and regions. It is a company valued at 178.47 billion dollars, with over 267,000 employees worldwide (Source: https://www.macroaxis.com/invest/market/PEP--valuation--WF 2018). WF Company is one of the largest food and drink company in North America and the second largest in the world, and is one of the three largest companies in this sector in Latin America. WF Company's presence in Latin America traces back to 1907, when the company registered the WF brand in Mexico. In 1938, it opened its first bottling plant in Mexico (WF, 2018). Regarding business units, the main four are: (1) WF Company America Foods (AAF) (WF Snacks North America (ASNA), WF Foods North America (AFNA) (2) WF Americas Beverages (AAB) (North American and Latin American beverage business) (3) WF Europe (berverage, food \& snack) (4) WF Asia, Middle East and Africa (AMEA) (beverage, food \& snack) (WF, 2014, 2017).

WF Company wide portfolio includes 22 brands, each generating over one billion U.S. dollars in annual retail sales (Source: https://www.statista.com/statistics/536974/wf-snumber-of-employees-worldwide/). In 2017, it's operating profit in Latin America was around $\$ 1.000$ billion US Dollars, which accounted for $11 \%$ of the company's operations worldwide. Over the course of more than 100 years, WF America business has grown to become one of the strongest foods and beverage manufacturers in the Latin America region, WF Latin America sells beverages, food and snacks throughout the region employing more than 70,000 employees in 34 countries and generating $\$ 7.2$ billion dollars in sales (WF, 2017).

\subsection{The Service Management Office (SMO) project at WF Company}

In 2011, WF Company went through a deep restructuring process, together with a productivity plan. This plan included actions related to aspects dealing with strengthening

\footnotetext{
1 Due to the company did not allow its name appears in this paper, WF Company (World food company) name is used instead.
} 
the complementary businesses in the food, snack and beverage areas by taking advantage of new technologies and processes in all of WF Company's operations, go-to-market strategies and information systems, thus increasing the focus on sharing best practices worldwide, consolidating manufacturing, warehousing and sales offices, and the application of simplified structures in the organization with wider spaces for control and fewer management strata (WF, 2014).

The above is an evidence that the use of information systems is a part of strategic operations at WF Company and, therefore, service management is an important element in order to make sure that IT services do add value to business strategies and processes. Achieving efficiency in such services has implied for the organization an evolutionary process in the incorporation of IT to their productive and business processes, based on the following principles (Lucio-Nieto \& Sanchez Trejo, 2010): Generate value for business units being serviced in Mexico through dependable, predictable service; innovate as a part of day-to-day living; generate productivity; being a source of talent for WF Company; and being a strategic business partner. Such evolution and embracing of principles has led WF Company's IT area, in a bit over a decade, to a series of transformations, as described below (Sanchez Trejo, 2017):

- Shift from a local function to a Shared Services model, integrating services and leveraging resources under an economy of scale.

- 1999-2006: establishment of a Shared Services model as a result of the consolidation of WF Company firms in Mexico, thus strengthening services under a Technology outsourcing model such as the Data Center and Telecommunication Services.

- 2006-2007: End user care services were integrated under a service multisourcing model, some of them include: Service Desk, as the single point of contact to address the demand for IT services; Field Services, which addresses the need for IT services in the field in a timely manner, thus establishing clear principles of Service Levels.

- 2008 - Up to date. Consolidating business applications in ERP and applications to address the needs of the single model for business processes that deal with WF Company's value chain in Mexico.

- Improving the IT Service model

- 2007-2009: A vision of IT is created based on a focus on customer satisfaction along all WF Company business units in Mexico.

- 2007-2009: A standard service portfolio is defined.

- 2008-2011: An operating model and a service-driven, process-based organization to support such management (under the ITSM principles) are created. 


\section{- IT Globalization (2011 up to date)}

- A new identity for IT is created with a global vision for all geographies where WF Company has presence throughout the world.

o Work is conducted under a model that seeks to maximize resource leveraging, thus generating productivity based on economies of scale with a focus on continual improvement and innovation processes.

\subsubsection{ITIL implementation at WF Company}

The relevant aspects of ITIL implementation in WF Company Latin America are described in this section. As mentioned above, in the 2000-2007 period, the IT organization was focused on seeing to it that everything that was done, would be of use a system for operation and marketing control, but by doing so the IT department lost the point of contact where they were close to the business and the end user, and the question arose: How to align IT with the business? As a part of the solution, a consulting firm was contracted and the first question had to do with the governance model, which was not consolidated. This revealed that the organization was not used to talk in such terms as: methodology, frameworks, governance, ITIL or COBIT (Ramírez, 2009). It was so to such an extent that in the initial stages of the implementation of ITIL, it was never seen as a stage where the individuals involved would say "we are implementing ITIL". Even the name ITIL itself was of little importance for IT personnel, for the only intent was to get organized so as "to be able to respond better to customers and users", because they were considered to be the ones who paid for service. Therefore, ITIL implementation came about because of the need to organize the operation of IT services. Here it must be stressed that this first stage of the implementation occurred after the company became organized in business units.

And so, the main objective of implementing ITIL practices was to improve and maintain an adequate level of quality, cost and time for technology services for the firm. The ITIL processes implemented were: incident management, problem management, change management and configuration management. In order to conduct this implementation, a cycle was implemented considering the following phases: initial assessment of the way the practices for such processes were, showing what could be done differently, joint design among areas and regions, internal training and certification in the implemented processes, coaching during operation start-up, execution by the company on its own, feedback and adjustment period (Lucio-Nieto \& Sanchez Trejo, 2010).

Considering the timeline for ITIL implementation, it began in 2008, as a local initiative in Mexico and, in view of the results, the processes began to be implemented in all other regions in Latin America. This execution was divided into 3 stages in order to consolidate the adoption of processes and achieve business objectives (Lucio-Nieto \& Sanchez Trejo, 2010). The rest of the implementations occurred by Region (which is the way they are 
organized in $\mathrm{BIS}^{2}$ in order to support the business) in this order: CARICAM September 2010 (Guatemala, Dominican Republic, Puerto Rico, Panama, Costa Rica, Honduras, El Salvador), the Andean Region February 2011 (Colombia, Ecuador, Peru and Venezuela), Brazil April 2011, South Cone Region June 2011 (Argentina, Uruguay, Chile); that is, 16 countries in all, where ITIL-based service delivery was implemented.

\subsubsection{ITIL operation and the need for an SMO}

The first implementation of ITIL at WF Company started in December 2008 (in Mexico) and was completed in mid-2011 (South Cone Region). Within this context, it became evident that there were regions with a far more advanced maturity level with regards to the operation of the four implemented processes. By the time ITIL implementation was completed for the South Cone Region, it had already been in operation in Mexico for a couple of years.

Although the Latin American sector was operating under ITIL processes (incident, problem, change and configuration management), in the same line, attempts were being made to stabilize process operation in each Region. A post-implementation review was conducted, which was intended to identify the level of maturity and compliance of the processes in all of the Regions. Such assessment revealed the existence of different maturity levels for the processes in the various Regions, and a series of needs were detected for both business and BIS that would eventually result in the implementation of an SMO. Among the needs that were identified as related to management it was found that there should not be large deviations in processes, so as to ensure that operation would be similar in the various Regions, that is, to align them so that they would be managed as processes.

\subsubsection{The creation of an SMO at WF Company}

As a result of BIS's concern to provide technology services to the highest quality standards in order to deliver business-oriented results such as: accelerating service solution times, having a positive impact on services related to critical sales / production / logistics / shipping processes, improving availability levels (Ramírez, 2011), and the results of the assessment described in the above section, the need to establish an SMO was identified, and its scope was stated as follows: (1) establish all Service Manager communication, who was responsible for Latin America's SMO, (2) establishing the mechanism or operating model to request changes or modifications to processes, tools or roles for the four processes that had been implemented, (3) do so through an audit scheme where a formal entity is located that oversees the way processes operate in all of the regions, so as to match this operation.

\footnotetext{
${ }^{2}$ Business Information and Solutions (BIS): name of the department in charge of managing WF Company Latin America's IT services. It was oriented towards installing four main ITIL processes: incident management, problem management, change management and configuration management.
} 
With regards to the participation of the SMO in the IT service design strategy, in 2012 the fundamental processes dealing with incidents, changes, configurations and problems were in place, which resulted in a one-year-long implementation of a governance model in terms of communication, where all indicators were revised - not process indicators, but business ones - so that they were aligned to BIS strategy in order to facilitate the availability of the services now existing for the business' value chain. The overall SMO model proposed is shown in Fig. 1.

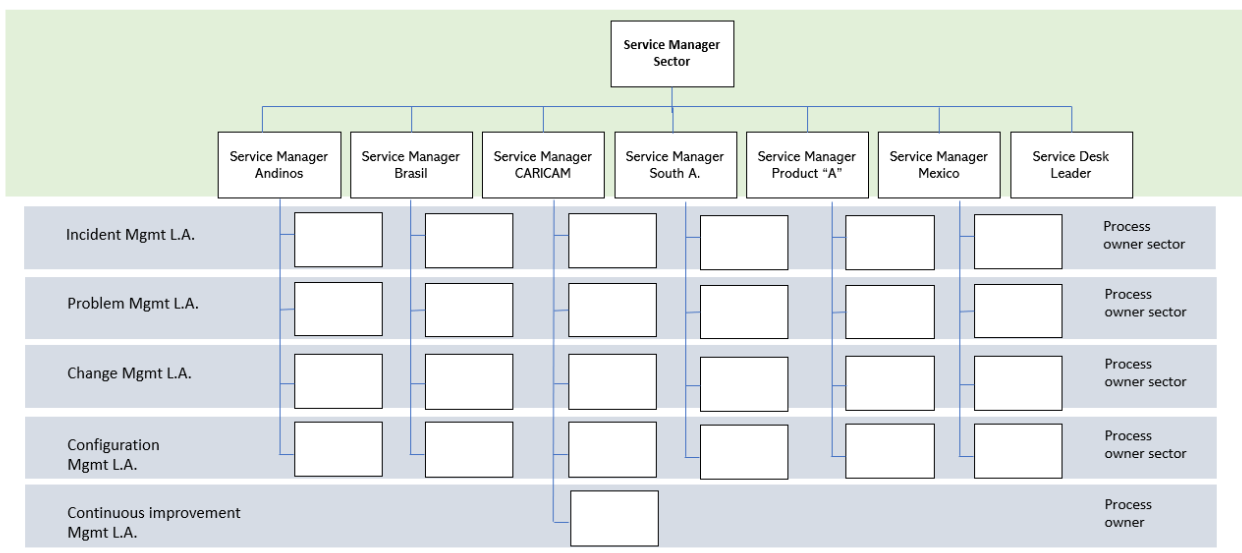

Fig. 1 SMO Model operating at WF Company Latin America

\subsection{Lessons learned}

While ITIL is one of the most widely used and recognized frameworks in IT service management (England, 2011; Gërvalla, Preniqi, \& Kopacek, 2018; Hirt \& Melander, 2010), it is not exempt from having weaknesses such as the fact that it only describes what has to be done for ITIL implementation; it even only suggests the creation of a Service Management Office (Cannon, 2011), but it fails to describe a methodology or guidelines on how to do so and, even more importantly, what to do after its implementation, and it also fails to provide a clear indication that it is an evolutionary process (Lucio-Nieto \& Sanchez Trejo, 2010). It should be emphasized that there is evidence that holding an ITIL certification is not a warranty of its adequate adoption or execution (England, 2011; Lucio Nieto \& González-Bañales, 2016; Pollard \& Cater-Steel, 2009) as evidenced in WF Company in the early stages of its implementation of ITIL. As a consequence, ITIL as a framework, requires taking care of a series of factors to achieve successful operation and functioning (Neničková, 2011), and one such factor is the operation of an SMO (Fry, 2008; 
Montgomery, 2011). In the case of WF Company, an SMO has been identified as a means for aligning the Service Management (SM) strategy, resources, processes and tools to business objectives.

Considering the above, the main lessons learned in the WF Company case in the implementation of an SMO for Latin America are described below. The lessons are classified in three categories: people, processes and technology, considered as ITIL postimplementation success factors (Iden \& Langeland, 2010; Neničková, 2011) and key elements to be considered in designing and operating an SMO (Roller, 2009).

\subsubsection{People}

The main challenges to be overcome - and the ones WF Company faced after implementing ITIL - were: Many priorities, which made it difficult to be $100 \%$ focused on compliance with ITIL processes or implementing more processes; personnel operated with individual objectives that were not aligned to the organizational goal, but the goal was not always related to BIS process execution, continual improvement or roles; what would happen with roles? People were saturated and there would not be more hiring; inadequate perception of ITIL, being perceived at times as the end in itself and not as the means for providing good service; inadequate skills for change management.

\subsubsection{Processes}

The processes defined to be run by the SMO are: communication management, execution of Committees at the three levels (Executive, Tactical and Operational), change management for SMO processes and tools. Additionally, the ITIL processes that are under its custody are: incident, problems, changes and configuration. The SMO provides support for governance and management of the processes together with control management and responsibility for field services (Peres , 2017).

Considering that the processes are a part of the success factors in IT service management, it should be taken into account that (1) adequate techniques and tools must be applied, (2) IT and the related business processes must be aligned, (3) there must be follow-up and measurement (Neničková, 2011; Pollard \& Cater-Steel, 2009), and (4) there must be a clear vision of the benefits of adequate process management both individually and as a set (Tan, Cater-Steel, \& Toleman, 2009).

In order to establish the criteria to be used to prioritize the processes to be implemented within the SMO, aspects related to technology, service and process governance for SM, application support and solution delivery were considered. Then, the following questions emerged: How does one go about innovating, being productive, making progress in terms of image and in terms of service quality? How to help transforming the business? What are the basic things one has to do in order to have a positive impact on the value chain for the 
main business processes in Latin America? The answer was: "going back to the basics", that is, making sure that what today is in a production environment is being offered in a standard way and making it more effective. The above defined the priority for what WF Company might call the "foundation" of SM.

\subsubsection{Technology}

Technology is considered to be one of the success factors in the implementation and postimplementation stages of ITSM frameworks (Aubry, Hobbs, Muller, \& Blomquist, 2010; Pollard \& Cater-Steel, 2009), and this applies to the SMO too - which is a part of it (LucioNieto et al., 2016). Considering that organizations nowadays depend upon the use of IT to execute their processes, maturity in systems and information architecture in general is necessary, because with robust and mature technologies it is possible to have processes and services that are available, timely and properly to the end users who require them. Its presence is specially vital when processes used within a shared service model are related with each other in some way (Roller, 2009).

\subsubsection{Main results of the implementation of the SMO at WF Company}

The process for implementation of the SMO at WF Company lasted two months and two post-implementation verifications were conducted to validate compliance of the objectives established for the SMO. It must be mentioned that SMO processes and practices were tailored to the specific needs of the company. Following is a description of the main results perceived from the implementation of the SMO in 2012 (Peres , 2017):

- The main improvement perceived has to do with the identification of opportunities and improvements regarding operation, that is, the identification and correction of all recurrent incidents thus improving availability times for business critical services. Additionally, indicators have been created that allow measuring business process availability and improve the visibility of the value delivered by IT as a business partner, together with the launching of a communication campaign based on a monthly bulletin featuring the main indicators, projects and main points to be followed during the month (Peres , 2011).

- The framework for definition of the SMO has been of use as a formal guide for process implementation vs. the best practices consulted, but more so from an execution than from an implementation standpoint, and with a focus on service for the organization.

- It has been identified that the SMO must be sustainable, thus ensuring in turn, that processes last, with an orientation towards continual improvement.

- The SMO has helped align IT efforts to deliver business value and generate results, thus optimizing costs in terms of service and integrating three aspects: new 
capacities (being able to have best practices), productivity (being able to have aspects such as resource leveraging for various business needs), and service quality (measuring user satisfaction), it all based on a tool allowing making decisions in a timely manner, which has been instrumental for BIS in terms of direction and operation.

- The main positive impacts of the SMO that have been identified: Elimination of "gray areas" regarding service management governance; elimination of meetings regarded as "on the fly", to find out how process management is doing; and results can be known in terms of benefits with measurable, quantifiable and sustainable indicators through time.

- Remarks from the personnel involved in the SMO have been: Service quality is being measured in terms of customer satisfaction and service performance; now there is awareness that indicators and commitments with the business are one thing, and the perception of people from the various areas receiving service (customer experience) is quite another, which allows for measurement through some mechanisms; and an SMO is a means, a complement, rather than the fundamental part, it goes beyond having an IT governance initiative; it reflects and displays the benefits of the way of working of BIS in business day-to-day operation.

- Prior to the implementation of the SMO there was an area known as Service Management, which focused on monitoring operation and performance. Since the SMO was designed, its focus has shifted, to a greater extent, towards service and process governance.

An assessment of new services, processes and tools is provided, and it raises awareness that it is important to get organized first in order to be able to be focused as an SMO. Just as the positive impacts have been identified; the negative ones have also been pin-pointed; they include: A perception of work overload by the personnel involved; natural resistance to change; knowing how to manage change in people, for rework has been generated in the process.

\section{Conclusions}

For WF Company Latin America's BIS area it is clear that IT must deliver capacities for the organization and for processes to provide an environment with integrated services, fully aligned to company objectives, and improvement in IT quality and cost (Lucio-Nieto \& 
Sanchez Trejo, 2010). This is a fact that has led this area to implement initiatives that have allowed managing IT services more efficiently, seeking to support the company's mission: “... being the first convenience food and drink company... offering value to investors while providing opportunities for growth and enrichment to our employees, our commercial partners and to the communities where we operate..."

The lessons learned in the evolutionary process of IT service management, from the ITIL implementation, up to the SMO, lead to conclude that the more people there is, the more communication is needed; that support is required not just from top management, but also from intermediate level managers and supervisors; that IT personnel need to be trained in the areas related to best practices in IT services; and, perhaps more relevantly, to realize that an evolutionary process is required where a part of the key to success in achieving better results is people and a focus on generating business value, that is, meeting customer actual needs such as Sales, Production, Logistics and other business areas (Lucio-Nieto \& Sanchez Trejo, 2010).

The greatest changes derived from the improvements in IT service management were being able to migrate from a function model to a service model: to go from management of cost by function to management by service; from an order taker to a focus on business transformation initiatives; from a portfolio management based on applications to a process based on flexible governance; from IT-based roles, to collaborative and cross-functional ones (Peres , 2017).

The case analyzed reveals, as the main challenge in the implementation of an SMO, change management in organizational culture and awareness raising regarding the importance of the inter-relation among IT service management processes as a part of a continual improvement process, for it implied making adjustments to the organizational structure in order to be able to define the SMO as the integrating point for processes, technology and people, to provide IT services to the whole organization in an efficient manner. In order to prioritize the process to be implemented within the SMO, technology, service and process governance must be taken into account for a more efficient management of SM services. An SMO must be sustainable, that is its benefit, because there must be roles allowing for constant evolution.

The authors consider that the results presented in this case may be applicable not just to companies sharing WF Company's characteristics: multinational and multiproduct, but they 
can also be extrapolated to other types of sectors. The SMO model analyzed (Lucio-Nieto, 2011; Lucio-Nieto \& Colomo-Palacios, 2012) was designed so that it could be adapted according to the IT service management needs of the company requiring it. Its bases are derived, mostly, from frameworks and best practices such as ITIL and COBIT, as commented by Rozemeijer (2007): "The available frameworks do not commonly fit as the pieces of a puzzle. In must be taken into account that they were created by different people, at different times, in different places, in different ways, for different reasons, focusing on different phases of the lifecycle, functions, processes, results and aspects, with varying degrees of granularity, precision, quality and consistency. Together they are an integrated image that can act as an umbrella to assist an organization in implementing multiple frameworks successfully." Considering the above, this work suggests the searching and documentation of the lessons learned by companies from various sectors in their processes for implementation of an SMO and an appraisal of their usefulness for IT service management.

\section{References}

Aubry, M., Hobbs, B., Muller, R., \& Blomquist, T. (2010). Identifying Forces Driving PMO Changes. Project Management Journal, 41(September), 30-45.

Cannon, D. (2011). Chapter 6. Organizing for service strategy. In The Stationery Office (Ed.), ITIL Service Strategy (pp. 317-339). The Stationery Office. ITIL Best Management Practice.

Cartlidge, A., Hanna, A., Rudd, C., Macfarlane, I., Windebank, J., \& Rance, S. (2007). An Introductory Overview of ITIL ${ }^{\circledR}$ V3 An Introductory Overview of ITIL ${ }^{\circledR}$ V3. (A. Cartlidge \& M. Lillycrop, Eds.). The UK Chapter of the itSMF.

England, R. (2011). Review of recent ITIL studies. Group. APM Group Ltd.

Fry, M. (2008). Building an ITIL based Service Management Department. TSO Information \& Publishing Solutions.

Gërvalla, M., Preniqi, N., \& Kopacek, P. (2018). IT Infrastructure Library (ITIL) framework approach to IT Governance. IFAC-PapersOnLine, 51(30), 181-185. https://doi.org/10.1016/j.ifacol.2018.11.283

Gómez, J. (2009). Conference: IT Evolution, the journey to improve IT Value. ITESM, Campus Monterrey, México.

Ramírez, J. (2011). Entrevista: Lecciones aprendidas de ITIL en WorldFoodCompany. ITESM, Campus Monterrey, México.

Hirt, T., \& Melander, L. A. (2010). ITIL: practice and theory an empirical study. Analysis. Norges Handelskhoyskole.

Hubbert, E. (2008). Role Overview: Service Manager, Delivering Value To Your Business By 
Facilitating Outcomes And Managing The Service. Retrieved from http://www.forrester.com/rb/Research/role_overview_service_manager/q/id/45786/t/2

Iden, J., \& Langeland, L. (2010). Setting the Stage for a Successful ITIL Adoption: A Delphi Study of IT Experts in the Norwegian Armed Forces. Information Systems Management, 27(2), 103-112. https://doi.org/10.1080/10580531003708378

ITGI. (2009). COBIT User Guide for Service Managers. Office. IT Governance Institute.

Lucio-Nieto, T. (2011). Service Management Office: De la teoría a la práctica. In ISACA (Ed.), ITGMS VISION11. Madrid, Spain.

Lucio-Nieto, T., \& Colomo-Palacios, R. (2012). ITIL and the creation of a Service Management Office (SMO): a new challenge for IT professionals. An exploratory study of Latin American Companies. In Second European Workshop on Computing and ICT Professionalism (EWCIP 2012). Madrid, Spain.

Lucio-Nieto, T., \& González-Bañales, D. L. (2019). Exploring ITIL® Implementation Challenges in Latin American Companies. International Journal of Information Technologies and Systems Approach, 12(1), 73-86. https://doi.org/10.4018/ijitsa.2019010105

Lucio-Nieto, T., González-Bañales, D. L., \& Bermeo Andrade, H. P. (2016). Service Management Office (SMO): an alternative for improving information technology management processes' capacity levels. Case: COTEMAR, México. In $5 o$ Congreso Internacional de Gestión Tecnológica y DE la Innovación (COGESTEC 2016). Bucaramanga, Colombia: COGESTEC. Retrieved from https://www.researchgate.net/publication/309566646_SERVICE_MANAGEMENT_OFFICE_S MO_AN_ALTERNATIVE_FOR_IMPROVING_INFORMATION_TECHNOLOGY_MANAGE MENT_PROCESSES'_CAPACITY_LEVELS_CASE_COTEMAR_MEXICO

Lucio-Nieto, T., \& Sanchez Trejo, L. (2010). We got it baby! How Incident and Problem management got immediate business results from ITIL Implementation. In Fusion 10, itSMF USA. itSMF USA.

Lucio Nieto, T., \& Gonzalez-Bañales, D. L. (2009). ITIL más allá de las fronteras: Un análisis de su estado actual en México y Latinoamérica. In IV Academic International Congress on IT Governance and Management. "Evolving from IT Service Management to IT Governance." Madrid, España: ITsMF Spain.

Lucio Nieto, T., \& González-Bañales, D. L. (2016). Prácticas de ITSM en México y Latinoamérica. Estudios anuales 2008-2013. Universidad Ibero Americana A.C.

Microsoft. (2008). Service Management Microsoft. Microsoft IT showcase.

Montgomery, J. (2011). 8 Steps to implementing a Service Management Office (SMO). Retrieved from http://www.plexent.com/blog/bid/56320/8-Steps-to-Implementing-a-Service-ManagementOffice-SMO

Neničková, H. (2011). Critical success factors for ITIL best practices usage. Economics and Management, 16, 839-845. 
Lessons learned from the implementation of a Service Management Office: the case of a World Food company in Latin America

Plexenet. (2011). Service Management Office Start-Up Kit (No. 972-381-0077). Service Management. Retrieved from www.plexent.com

Pollard, C., \& Cater-Steel, A. (2009). Justifications , Strategies , and Critical Success Factors in Successful ITIL Implementations in U . S . and Australian Companies : An Exploratory Study. Information Systems Management, 2(26), 164-165. https://doi.org/10.1080/10580530902797540

Roller, S. (2009). The Service Management Office. The Role of Integrated Governance and the ITIL V3. Proactive.

Rozemeijer, E. (2007). Frameworks for It Management: A Pocket Guide. Van Haren Publishing.

Peres, J. (2017). Entrevista: Lecciones aprendidas SMO WordlFoodCompany Latino América. ITESM, Campus Monterrey, México.

Shahsavarani, N., \& Shaobo, J. (2011). Research in Information Technology Service Management (ITSM): Theoretical Foundation and Research Topic Perspectives. In International Conference on Information Resources Management (CONF-IRM). AIS Electronic Library (AISelL). Retrieved from http://aisel.aisnet.org/confirm2011/30/

Tan, W.-G., Cater-Steel, A., \& Toleman, M. (2009). Implementing IT Service Management: A case study focussing on critical success factors. Journal of Computer Information Systems, (Winter).

WF. (2014). The power of WorldFoodCompany 2014 Annual Report. Retrieved July 5, 2012, from https://www.wf.com/docs/album/default-document-library/WF-2014-annual-report_final.pdf

WF. (2017). Annual Report 2017 WF Company. Retrieved from https://www.wf.com/docs/album/annual-reports/WF-inc-2017-annual-report.pdf

WF. (2018). WF: nuestra historia. Retrieved July 1, 2012, from http://www.wf.com.mx/Media/DataSheet-Major-Business-Units.html 